\title{
Combined effect of using static traction in some therapeutic methods to reduce knee arthritis symptoms
}

\author{
DR / Waleed M. Hedya
}

\section{Introduction}

Osteoarthritis is a common musculoskeletal disease and leads to functional drop and loss in quality of life. Clinically, the condition is described by joint pain, tenderness, crepitus, stiffness and limitation of movement with occasional effusion and variable degrees of local inflammation (Pereir et al., 2015).

The pain in knee osteoarthritis is frequently activity associated; constant pain frequently becomes a feature later in the disease (Syed and Wani 2014). Pain in knee osteoarthritis is not simply attributable to the structural modifications in the affected joint, but the consequence of interaction between structural modification, peripheral and central pain processing mechanisms (Eitner et al., 2017).

However, pain is not the only consequence of knee osteoarthritis experienced by patients. Pain is associated with function, with physical movements triggering pain, while pain, in turn, causes limitations in physical function (Castrogiovanni and Musumeci 2017).

There are many risk factors linked with knee osteoarthritis, commonly - joint dysplasia, intra articular fractures, meniscal injuries etc. osteoarthritis has often been found to be linked with occupation involving repetitive stress to the joint in the form of bending activities, operation of heavy vibrating tools, long term farming (Bardoloi et al., 2017).

Sports that subject joints to repetitive high levels of impact and torsional loading raise the risk of articular cartilage degeneration and the subsequent clinical syndrome of knee osteoarthritis. These people and those with early osteoarthritis can benefit from regular physical activity, but they should have a careful evaluation of their joint structure and function before participation. They should consider measures that decline the intensity and frequency of impact and torsional loading of joints, including use of sports equipment that declines joint impact loading, improving muscle strength, tone, and general conditioning so that muscle contractions support protect joints from injury and high impact, and reducing body weight (Buckwalter and lane 1997; Wheaton and Jensen 2010). 
To maximize the functional capacity of patients with knee osteoarthritis, therapeutic exercise programs that emphasize stretching, strengthening and conditioning and education and that are personalized to disease severity and patients' individual musculoskeletal abnormalities are recommended (Kunduracilar et al., 2018). Many people with knee osteoarthritis are capable of performing independent exercise programs with an objective of improving physical fitness, and some need personalized exercise instruction and support to be able to participate in rehabilitation programs and to maintain health, improve function, and decrease their risk of inactivity-related illness (Sisto and Malanga 2006).

Transcutaneous electrical nerve stimulation (TENS) is usually used to treat the pain of knee osteoarthritis, stimulation was effective in decreasing knee pain and statistically significant results favoring for relief of knee stiffness and increase in long-term pain relief (Brosseaul et al., 2004).

The effects of electrical muscles stimulation (EMS) have been studied in a variety of patient populations which involved patients recovering from total knee replacement, anterior cruciate reconstruction, knee osteoarthritis and stroke patients, and there is no consensus regarding the therapeutic effectiveness of EMS in a extensive variety of patient populations (Hasegawa et al., 2011).

Ultrasound (US) is one of the commonly used nonpharmacological treatment methods for knee osteoarthritis. Many studies were recognized that, significant improvements in terms of pain, function, and quality of life scales were noted in osteoarthritis ultrasound treated group in comparison with the other groups (Yildiz et al., 2015).

Studies have shown that cooling can be an efficient in decreasing the pain for knee osteoarthritis and improving of the knee function (Alberca et al., 2017).

Studies proved that, mechanical joint traction of the knee using an external fixing device on patients with knee osteoarthritis showed hopeful results. It enlarged the joint space and cartilage thickness, reduced the area of lost brain areas, and improved the total function (Intema et al., 2011; Alpayci et al., 2013).

The present study aimed at assessing the combined effect of using static traction in some therapeutic methods to reduce knee arthritis symptoms for reducing the pain and improving the quality of patients' life.

\section{Materials and methods}

\subsection{Study sample}


The study sample comprised twenty four players (30-45 years-old) diagnosed with knee osteoarthritis, had no issues of blood pressure, pulse, and breathing, they also had no consciousness or sensory disorders. The sample was selected from team sports player (basketball, handball, volleyball and five-a-side football) whose participant in the periodic of Egyptian companies, the study was applied from March 2017 to May 2018.

\subsection{Study domains}

\subsubsection{Study time}

Period: From March 2017- May 2018.

\subsubsection{Study place}

Study was performed at health and sport scientific center Port Said.

\subsection{Study approach}

Study was performed using experimental approach.

\subsection{Experimental setup and working}

The study sample was divided randomly to three subsample, the first was treated with the traditional treatment method (therapeutic exercise programs, TENS / EMS, ultrasound (US) and cooling), the second was treated same as the first with addition static knee joint traction treatment, done separately, and the last one combined all treatment methods with exception that the static traction and TENS / EMS were done at the same time.

\subsubsection{Therapeutic exercise programs}

Therapeutic exercise program should include periods of warm-up, aerobic exercise, and cool-down that include exercises to improve or maintain flexibility, range of motion (ROM), muscle strength and endurance, and cardiovascular fitness and health (Sisto and Malanga 2006).

Warm-up strategy may improve subsequent performance but only if the duration of the warm-up strategy is $\leq 16$ min (McGowan et al., 2015).

Table 2.1: Warm up exercise name, volume and mode

\begin{tabular}{|l|l|c|l|}
\hline \multicolumn{1}{|c|}{ Exercises } & \multicolumn{2}{c|}{ Volume } & \multicolumn{1}{c|}{ Mode } \\
\hline Lunges with unilateral trunk rotation (2 sides) & 4 sets & $10 \mathrm{~s}$ & Static \\
\hline Lunges with unilateral trunk rotation & 4 sets & $8 \mathrm{reps}$ & Dynamic \\
\hline
\end{tabular}




\begin{tabular}{|l|c|l|l|}
\hline Elbow extension (sprawl) & 4 sets & $20 \mathrm{~s}$ & Isometric \\
\hline Superman & 4 sets & $20 \mathrm{~s}$ & Isometric \\
\hline Static crunches with hip abduction & 4 sets & $20 \mathrm{~s}$ & Static \\
\hline Static crunches with hip flexed and trunk rotations (2 sides) & 3 sets & $10 \mathrm{~s}$ & Static \\
\hline Static crunches with trunk rotations lying down (2 sides) & 3 sets & $10 \mathrm{~s}$ & Static \\
\hline Static crunches with trunk rotations standing-up (2 sides) & 3 sets & $10 \mathrm{~s}$ & Static \\
\hline Static elbow extension with unilateral knee flexion (2 sides) & 3 sets & 10 reps & Dynamic \\
\hline Standing from the guard (2 sides) & 3 sets & 10 reps & Dynamic \\
\hline
\end{tabular}

reps $=$ repetitions.

(Bidonde et al., 2015) recommends that, for aerobic exercise, most adults should involve moderate-intensity cardiorespiratory exercise training using large muscle groups and rhythmical activities for 30 minutes per day on three sessions per week for a total of 90 minutes.

Table 2.2: Aerobic exercise name and volume

\begin{tabular}{|c|c|c|c|}
\hline \multicolumn{4}{|c|}{ (static stretching) } \\
\hline Exercises & \multicolumn{3}{|c|}{ Volume } \\
\hline Adductors & $3 \mathrm{re}$ & & $10 \mathrm{~s}$ \\
\hline Hamstrings & $3 \mathrm{re}$ & & $10 \mathrm{~s}$ \\
\hline Abductors & $3 \mathrm{re}$ & & $10 \mathrm{~s}$ \\
\hline Shoulders & $3 \mathrm{re}$ & & $10 \mathrm{~s}$ \\
\hline \multicolumn{4}{|c|}{ (dynamic stretching) } \\
\hline Backward roll & 2 sets & $30 \mathrm{~s}$ & 10 reps \\
\hline Base changes for the abductors & 2 sets & $30 \mathrm{~s}$ & 10 reps \\
\hline Scorpion for shoulders and trunk & 2 sets & $30 \mathrm{~s}$ & 10 reps \\
\hline Hip abduction & 2 sets & $30 \mathrm{~s}$ & 10 reps \\
\hline
\end{tabular}

After training, a low-intensity cool-down session should be implemented to facilitate a gradual transition from an exercise level to a resting state. A cool-down period is essential after a training session and should last approximately 5-10 minutes (Costa et al., 2015).

Table 2.3: Cool-down exercise name, volume and mode

\begin{tabular}{|l|c|c|c|}
\hline \multicolumn{1}{|c|}{ Exercises } & \multicolumn{2}{c|}{ Volume } & Mode \\
\hline Frontal scorpion & 2 sets & $30 \mathrm{~s}$ & Static \\
\hline Spinal extension for the abdomen and hip flexors & 2 sets & $30 \mathrm{~s}$ & Static \\
\hline Backward roll for the cervical and lumbar spine & 2 sets & $30 \mathrm{~s}$ & Static \\
\hline Lateral base for the gluteus and lumbar spine & 2 sets & $30 \mathrm{~s}$ & Static \\
\hline
\end{tabular}

\subsubsection{Transcutaneous electrical nerve stimulation (TENS)}

Brief-intense TENS (BITENS), pulses of long duration $(0.9 \mathrm{~ms})$ are set at high frequency $(150 \mathrm{~Hz})$ and sensory, motor, and nociceptor fibers are stimulated. This 
treatment was applied for 20min/day (Rongsawad and Ratanapinunchai 2018) participant received 18 sessions as 3 sessions/week.

\subsubsection{Electrical muscles stimulation (EMS) training:}

The electrical stimulator delivered a constant current symmetrical biphasic waveform with pulse duration of $100 \mu$ s and a frequency of $50 \mathrm{~Hz}$. Each EMS session consisted of 10 muscle contractions. Each contraction lasted 10 seconds and a rest interval was detected between each contraction. The EMS intensity (mA) was set according to each participant's tolerance level (Karthikeyan and Moorthy 2016). Each EMS session was applied for 20-min/day, EG participant received 18 sessions as 3sessions/week.

\subsubsection{Ultrasound (US)}

In US therapy (frequency: $1 \mathrm{MHz}$, intensity: $1.5 \mathrm{~W} / \mathrm{cm} 2$, duration: $8 \mathrm{~min}$ ) was applied to the anterior, medial, and lateral areas of the knees bilaterally (Yildiz et $a l ., 2015)$. The treatment was applied for three days a week for six weeks.

\subsubsection{Cold therapy}

Cooling with cold gel pack with fabric covered applied directly to the skin of the injured knee for 20-30 minutes at least once per day (Shehata and Fareed 2013).

\subsubsection{The static traction}

In the static traction, participants were asked to turn their hip and knee joints at 60 degrees in the supine position. The tibia was protected with a strap, and continuous knee joint traction treatment was applied to pull the tibia in the cephalocaudal direction. The force applied by the traction was around $6 \%$ of the participant's weight, and traction continued for 20 minutes at a stretch. This treatment was run for 20 minutes continuously, once a day, and three times a week for six weeks (Lee et al., 2018).

\subsubsection{Tools:}

In order to achieve the aim of the study, two tools were utilized to collect the data. These tools are as follows:

Tool I: Measuring test: As the knee movement range using the goniometer (Hancock et al., 2018), knee circumference using measuring tape (Silva et al., 2014), and knee anterior and posterior thigh muscles strength using dynamometer (Mentiplay et al., 2015). 
Tool II: Knee injury and osteoarthritis outcome score (KOOS): It was to assess patients' opinion about their knee and associated problems. The English version was used. It consists of five main parts as follow: Part one (pain), part two (symptoms), part three (activities of daily living) (ADL), part four (sport and recreation) (Sport/Rec) and part five (quality of life) (QOl) (Roos and Lohmander 2003; Shehata and Fareed 2013).

\section{Results and discussion}

No study participant left the research project for any reason. No side effects or complications were observed during the treatment.

Data collected using different measuring tools, revealed that there were improvements in knee measurements in pre compared to the post measuring tests for the three experimental groups with different three treating programs. The maximum improvement was detected with the third experimental groups, compared with the second and the first groups, after six weeks of treating using different treating programs. Results were presented in Tables 3.4-3.6 and Figure 3.1.

Treatment of OA aims to decrease joint pain and stiffness, preserve and increase joint mobility, decrease physical limitations, increase the quality of life, prevent further joint damage, and educate patients about the course and results of the disease. The use of physical treatment modalities is vital due to the considerable gastrointestinal and cardiac side effects of pharmacological agents commonly used in the treatment of OA, which is an important issue especially for the geriatric patients (Bhatia et al., 2013).

TENS study results is in line with Samuel and Maiya (2015) who reported that, TENS preferentially depolarizes sensory nerve fibers, and modulates pain through both opiate and non-opiate mechanisms, with quick start but short duration of analgesia; patients perceive this mode as the most comfortable form of TENS which improving subjective outcomes in patients with pain due to knee osteoarthritis.

EMS increases muscle oxidative capacity and enhances glucose disposal (Buuren et al., 2015). Many studies has provided strong evidence representing that electrical muscular stimulation has been suggested as a method for increasing strength of the quadriceps femoris and decreasing pain in knee osteoarthritis (Giggins et al., 2012). 
US, which is among the most usually used physical treatment methods, is a deep heating modality with analgesic and antispasmodic effects on muscles. Analgesic efficacy of therapeutic US outcome may be because of thermal and nonthermal effects. Thermal effects lead to a decrease in pain sensation by affecting tissue metabolism, capillary permeability, pain threshold, and an increase in tissue elasticity. Non-thermal effects reduce pain sensation by stimulating tissue regeneration, altering cell membrane permeability, and increasing the intracellular calcium entrance to the neural system (BAPMR 2013; Yildiz et al., 2015).

Cooling study results are in line with Brosseau et al. (2003); Kuyucu et al. (2015); who reported that the application of ice packs for three weeks is followed by some enhancement in pain. Using cold treatment can decrease the pain and stiffness and reduce inflammation and swelling.

The result of current study shows that traction had enhancing effect in management of osteoarthritis knee joint. The enhancement in functional result from the application of traction may be because of relief of abnormal pressure on nociceptive receptor systems. Effects of traction involved increased vascular and lymphatic flow (suction aspiration effect) which tends to decrease stasis, edema and coagulates in chronic congestions. Traction stimulates proprioceptive reflexes and helps to tone muscles, which tend to decrease fatigue and restore elasticity and resiliency (Teichtahl et al., 2003).

Table 3.4: Mean, standard deviation, difference, difference (\%) and t-test between pre and post measurements for first group.

\begin{tabular}{|c|c|c|c|c|c|c|c|c|}
\hline \multirow{2}{*}{\multicolumn{2}{|c|}{ Knee measurements }} & \multicolumn{2}{|c|}{ Pre } & \multicolumn{2}{|c|}{ Post } & \multirow{3}{*}{$\begin{array}{c}\text { Difference } \\
15\end{array}$} & \multirow{3}{*}{$\begin{array}{c}\begin{array}{c}\text { Difference } \\
(\%)\end{array} \\
9.39\end{array}$} & \multirow{3}{*}{$\begin{array}{l}\text { t-value } \\
-9.92 *\end{array}$} \\
\hline & & \multirow{2}{*}{$\begin{array}{c}\text { Mean } \\
159.75\end{array}$} & \multirow{2}{*}{$\begin{array}{l}\mathbf{S D D} \\
4.71\end{array}$} & \multirow{2}{*}{$\begin{array}{l}\text { Mean } \\
174.75\end{array}$} & \multirow{2}{*}{$\begin{array}{l}\mathbf{E S D} \\
2.82\end{array}$} & & & \\
\hline $\overrightarrow{\Xi_{0}}$ & Extension & & & & & & & \\
\hline$\sum^{e}$ & Flexion & 48.75 & 5.34 & 32.50 & 3.34 & -16.52 & -33.33 & -6.52 \\
\hline \multirow{3}{*}{ 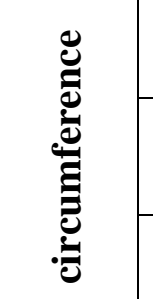 } & Mid patella & 47.50 & 2.45 & 45.25 & 2.12 & -2.25 & -4.74 & $-9.00 *$ \\
\hline & Above $7 \mathrm{~cm}$. & 51.00 & 2.62 & 49.25 & 2.60 & -1.75 & -3.43 & $-10.69^{*}$ \\
\hline & Below $7 \mathrm{~cm}$. & 43.88 & 2.59 & 42.50 & 3.25 & -1.38 & -3.13 & $-1.02 *$ \\
\hline 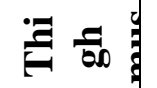 & Anterior & 16.88 & 3.14 & 22.25 & 3.15 & 5.38 & 31.85 & $-20.43 *$ \\
\hline
\end{tabular}




\begin{tabular}{|c|c|c|c|c|c|c|c|c|}
\hline & Posterior & 9.62 & 1.41 & 13.50 & 1.20 & 3.88 & 40.26 & $-9.64 *$ \\
\hline \multirow{5}{*}{$\begin{array}{l}y \\
\tilde{y} \\
y\end{array}$} & Pain & 27.56 & 2.96 & 38.53 & 3.63 & 10.96 & 39.77 & $-5.50 *$ \\
\hline & Symptom & 21.86 & 3.03 & 38.43 & 3.58 & 16.57 & 75.79 & $-9.10 *$ \\
\hline & ADL & 23.33 & 2.46 & 35.74 & 3.07 & 12.42 & 53.23 & $-7.61 *$ \\
\hline & Sport/Rec & 16.26 & 1.82 & 29.37 & 3.44 & 13.11 & 80.61 & $-10.55^{*}$ \\
\hline & QOL & 18.80 & 3.22 & 33.61 & 2.99 & 14.81 & 78.80 & $-9.72 *$ \\
\hline
\end{tabular}

T critical at alpha $0.05=1.89 *$

Table 3.5: Mean, standard deviation, difference, difference (\%) and t-test between pre and post measurements for second group.

\begin{tabular}{|c|c|c|c|c|c|c|c|c|}
\hline \multirow{2}{*}{\multicolumn{2}{|c|}{ Knee measurements }} & \multicolumn{2}{|c|}{ Pre } & \multicolumn{2}{|c|}{ Post } & \multirow{3}{*}{$\begin{array}{c}\text { Difference } \\
17.00\end{array}$} & \multirow{3}{*}{$\begin{array}{c}\begin{array}{c}\text { Difference } \\
(\%)\end{array} \\
10.56\end{array}$} & \multirow{3}{*}{$\begin{array}{c}\text { t-value } \\
-8.21 *\end{array}$} \\
\hline & & \multirow{2}{*}{$\begin{array}{l}\text { Mean } \\
161.00\end{array}$} & \multirow{2}{*}{$\begin{array}{l}\mathbf{E S D} \\
5.24\end{array}$} & \multirow{2}{*}{$\begin{array}{l}\text { Mean } \\
178.00\end{array}$} & \multirow{2}{*}{$\begin{array}{l}\mathbf{S D} \\
2.14\end{array}$} & & & \\
\hline 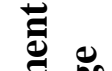 & Extension & & & & & & & \\
\hline$\sum^{e}$ & Flexion & 48.00 & 3.85 & 28.25 & 2.92 & -19.75 & -41.15 & -10.57 \\
\hline \multirow{3}{*}{ 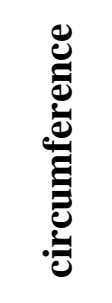 } & Mid patella & 48.13 & 2.30 & 45.00 & 2.39 & -3.13 & -6.50 & $-25.00 *$ \\
\hline & Above $7 \mathrm{~cm}$. & 50.75 & 1.91 & 48.25 & 1.67 & -2.50 & -4.93 & $-13.23^{*}$ \\
\hline & Below 7 cm. & 44.25 & 2.49 & 40.88 & 2.23 & -3.38 & -7.63 & $-18.44^{*}$ \\
\hline \multirow{2}{*}{ 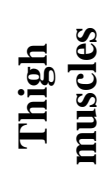 } & Anterior & 16.38 & 3.58 & 23.00 & 3.51 & 6.63 & 40.46 & $-25.19^{*}$ \\
\hline & Posterior & 8.63 & 1.77 & 14.13 & 1.96 & 5.50 & 63.77 & $-16.80^{*}$ \\
\hline \multirow{3}{*}{$\begin{array}{l}y \\
0 \\
0 \\
0\end{array}$} & Pain & 24.33 & 3.38 & 53.82 & 3.15 & 29.49 & 121.22 & $-28.58^{*}$ \\
\hline & Symptom & 20.52 & 1.97 & 55.84 & 3.21 & 35.32 & 172.10 & $-26.98 *$ \\
\hline & ADL & 24.46 & 2.13 & 50.72 & 3.35 & 26.26 & 107.35 & $-27.57^{*}$ \\
\hline
\end{tabular}




\begin{tabular}{|c|c|c|c|c|c|c|c|c|}
\hline & Sport/Rec & 21.26 & 2.54 & 45.00 & 3.78 & 23.75 & 111.71 & $-12.61^{*}$ \\
\cline { 2 - 8 } & QOL & 22.66 & 2.65 & 49.23 & 2.14 & 26.56 & 117.20 & $-25.14^{*}$ \\
\hline
\end{tabular}

Table 3.6: Mean, standard deviation, difference, difference (\%) and t-test between pre and post measurements for third group.

\begin{tabular}{|c|c|c|c|c|c|c|c|c|}
\hline \multirow{2}{*}{\multicolumn{2}{|c|}{ Knee measurements }} & \multicolumn{2}{|c|}{ Pre } & \multicolumn{2}{|c|}{ Post } & \multirow{3}{*}{$\begin{array}{c}\text { Difference } \\
22.00\end{array}$} & \multirow{3}{*}{$\begin{array}{c}\begin{array}{c}\text { Difference } \\
(\%)\end{array} \\
13.97\end{array}$} & \multirow{3}{*}{$\begin{array}{l}\text { t-value } \\
-29.10^{*}\end{array}$} \\
\hline & & \multirow{2}{*}{$\begin{array}{l}\text { Mean } \\
157.50\end{array}$} & \multirow{2}{*}{$\begin{array}{c} \pm \text { SD } \\
4.50\end{array}$} & \multirow{2}{*}{$\begin{array}{l}\text { Mean } \\
179.50\end{array}$} & \multirow{2}{*}{$\begin{array}{l} \pm \text { SD } \\
3.66\end{array}$} & & & \\
\hline$\vec{E}$ & Extension & & & & & & & \\
\hline$\sum_{1}^{\infty}$ & Flexion & 50.00 & 5.45 & 26.25 & 2.71 & -23.75 & -47.50 & -11.39 \\
\hline \multirow{3}{*}{ 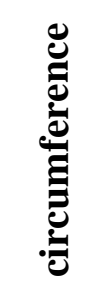 } & Mid patella & 47.00 & 3.07 & 43.38 & 2.97 & -3.53 & -7.71 & $-9.67 *$ \\
\hline & Above $7 \mathrm{~cm}$. & 50.13 & 2.30 & 47.00 & 2.73 & -3.13 & -6.23 & $-8.92 *$ \\
\hline & Below $7 \mathrm{~cm}$. & 43.13 & 2.75 & 39.38 & 2.13 & -3.75 & -8.70 & $-9.10^{*}$ \\
\hline \multirow{2}{*}{ 点 } & Anterior & 16.25 & 3.06 & 24.13 & 3.04 & 7.88 & 48.47 & $-15.28 *$ \\
\hline & Posterior & 10.00 & 2.27 & 17.13 & 2.47 & 7.13 & 71.25 & $-31.45^{*}$ \\
\hline \multirow{5}{*}{$\begin{array}{l}0 \\
0 \\
0 \\
0\end{array}$} & Pain & 24.64 & 2.32 & 61.10 & 3.38 & 36.46 & 184.00 & $-29.66^{*}$ \\
\hline & Symptom & 20.99 & 2.46 & 67.85 & 2.01 & 46.86 & 223.26 & $-75.28 *$ \\
\hline & ADL & 23.54 & 2.44 & 61.40 & 3.15 & 37.86 & 160.81 & $-27.80^{*}$ \\
\hline & Sport/Rec & 18.11 & 1.77 & 58.76 & 3.45 & 40.65 & 224.48 & $-31.18 *$ \\
\hline & QOL & 18.74 & 2.76 & 64.84 & 2.88 & 46.10 & 245.97 & $-30.02 *$ \\
\hline
\end{tabular}




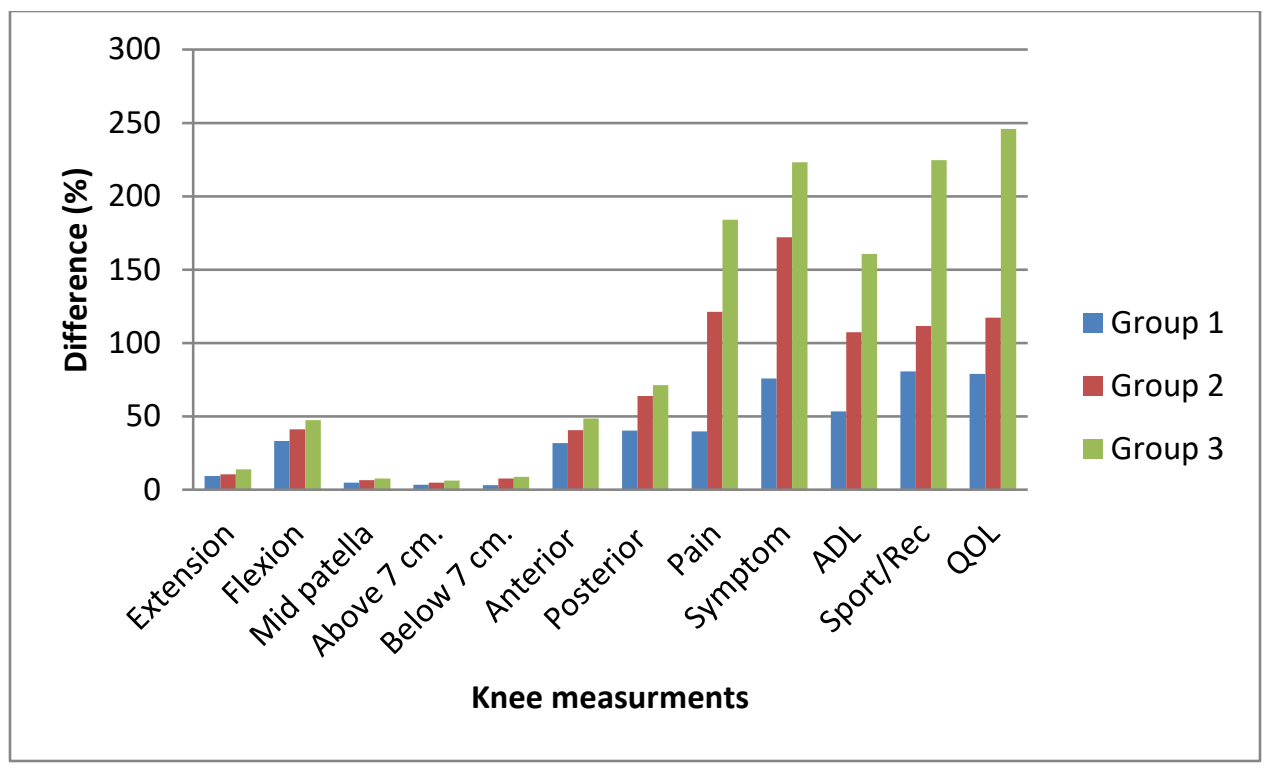

Figure3.1. Difference (\%) of knee measurements of the three experimental groups, using three different treating programs.

Data analysis indicated significant variations $(\mathrm{P}<0.01)$ in knee measurements among three different experimental groups, using three different treating programs (Table 3.7, 3.8).

The maximum improvement was detected with the third experimental groups, compared with the second and the first groups, these results are in line with Jagtap and Shanmugam (2014); who reported that various traditional approaches are used in treating osteoarthritis of knee joint but their study shows that ultrasound and exercises alone shows minimal effect in reduction of pain than compared to traction along with ultrasound and exercises. Traction was more effective in decreasing pain and improving quality of life than using conventional therapy alone.

Table 3.7: ANOVA test for variation in knee measurements among the three different experimental groups

\begin{tabular}{|c|c|c|c|c|c|c|}
\hline \multicolumn{2}{|c|}{$\begin{array}{c}\text { Knee } \\
\text { measurements }\end{array}$} & $\begin{array}{l}\text { Source of } \\
\text { variation }\end{array}$ & SS & df & MS & $\mathbf{F}$ \\
\hline \multirow{6}{*}{ 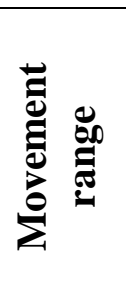 } & \multirow{3}{*}{ Extension } & Between groups & 94.33 & 2.00 & 47.17 & 5.46 \\
\hline & & Within groups & 181.50 & 21.00 & 8.64 & \\
\hline & & Total & 275.83 & 23.00 & & \\
\hline & \multirow{3}{*}{ Flexion } & Between groups & 163.00 & 2.00 & 81.50 & 9.06 \\
\hline & & Within groups & 189.00 & 21.00 & 9.00 & \\
\hline & & Total & 352.00 & 23.00 & & \\
\hline U. & Mid patella & Between groups & 16.58 & 2.00 & 8.29 & 1.31 \\
\hline
\end{tabular}




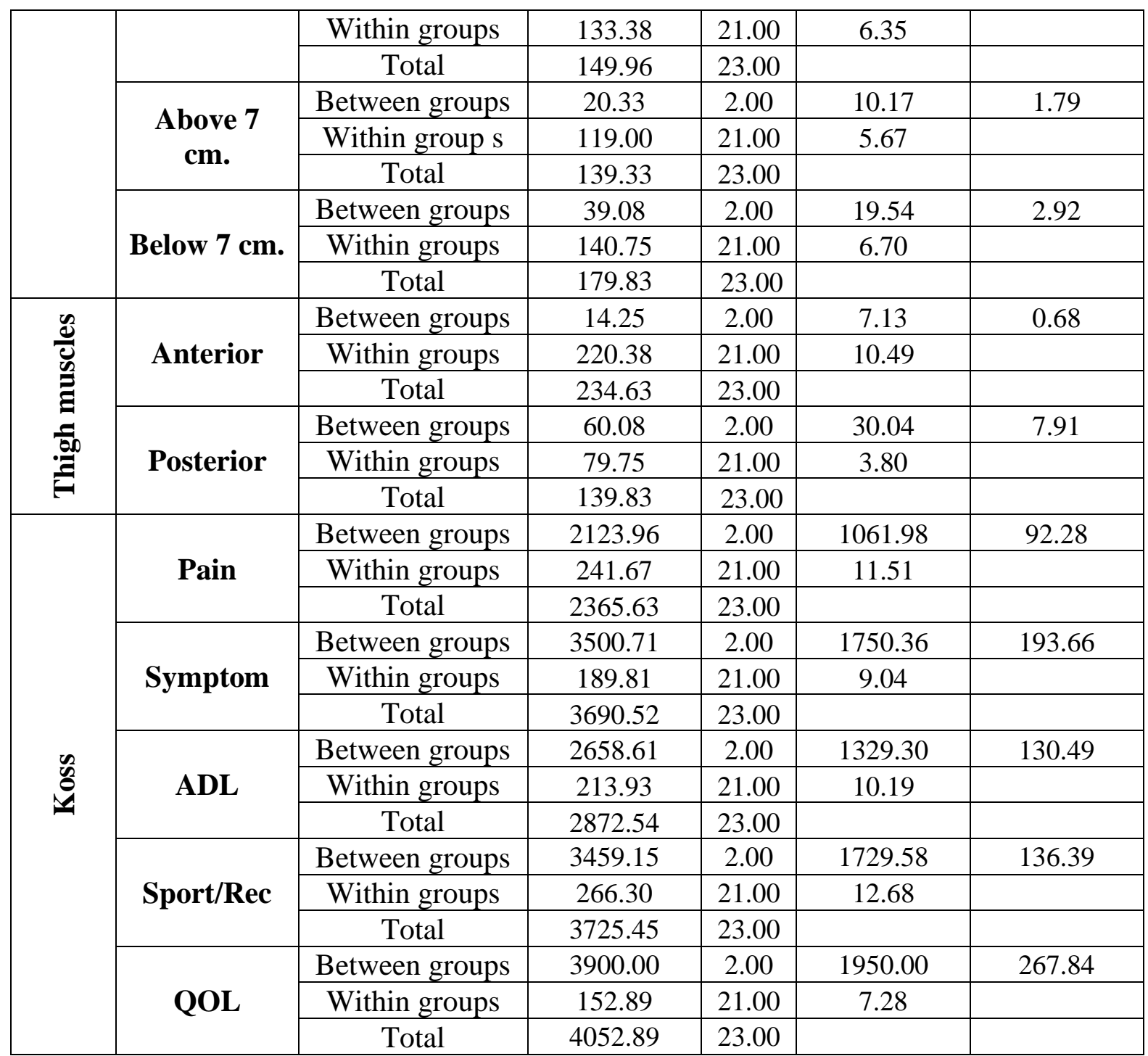

F critical at alpha $0.05=$

Sum of squares (SS), degree of freedom (df), mean sum of squares (MS) and F stat (F).

Table 3.8: Difference meaning level among mean of knee measurements for the three different experimental groups using L.S.D test

\begin{tabular}{|c|c|c|c|c|c|c|c|}
\hline \multirow{2}{*}{\multicolumn{2}{|c|}{$\begin{array}{c}\text { Knee } \\
\text { measurements }\end{array}$}} & \multirow{3}{*}{$\begin{array}{c}\begin{array}{c}\text { Experimental } \\
\text { groups }\end{array} \\
\text { Group } 1\end{array}$} & \multirow{3}{*}{$\begin{array}{l}\text { Mean } \\
174.75 \\
\end{array}$} & \multicolumn{3}{|c|}{ Mean differences } & \multirow[b]{2}{*}{ L.S.D } \\
\hline & & & & $\begin{array}{c}\text { Group } \\
1\end{array}$ & $\begin{array}{c}\text { Group } \\
2\end{array}$ & $\begin{array}{c}\text { Group } \\
\mathbf{3} \\
\end{array}$ & \\
\hline \multirow{6}{*}{ 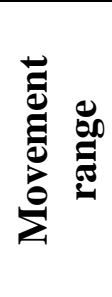 } & \multirow{3}{*}{ Extension } & & & - & $3.25 *$ & $4.75^{*}$ & \multirow{3}{*}{3.06} \\
\hline & & Group 2 & 178.00 & & - & 1.50 & \\
\hline & & Group 3 & 179.50 & & & - & \\
\hline & \multirow{3}{*}{ Flexion } & Group 1 & 32.50 & - & $-4.25 *$ & $-6.25^{*}$ & \multirow{3}{*}{3.12} \\
\hline & & Group 2 & 28.25 & & - & -2.00 & \\
\hline & & Group 3 & 26.25 & & & - & \\
\hline
\end{tabular}




\begin{tabular}{|c|c|c|c|c|c|c|c|}
\hline \multirow{9}{*}{ } & \multirow{3}{*}{ Mid patella } & Group 1 & 45.25 & - & -0.25 & -1.88 & \multirow{3}{*}{2.62} \\
\hline & & Group 2 & 45.00 & & - & -1.63 & \\
\hline & & Group 3 & 43.38 & & & - & \\
\hline & \multirow{3}{*}{$\begin{array}{c}\text { Above } 7 \\
\text { cm. }\end{array}$} & Group 1 & 49.25 & - & -1.00 & -2.25 & \multirow{3}{*}{2.48} \\
\hline & & Group 2 & 48.25 & & - & -1.25 & \\
\hline & & Group 3 & 47.00 & & & - & \\
\hline & \multirow{3}{*}{$\begin{array}{c}\text { Below } 7 \\
\text { cm. }\end{array}$} & Group 1 & 45.25 & - & -0.25 & -1.88 & \multirow{3}{*}{2.69} \\
\hline & & Group 2 & 45.00 & & - & -1.63 & \\
\hline & & Group 3 & 43.38 & & & - & \\
\hline \multirow{6}{*}{ 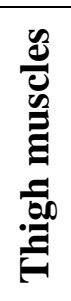 } & \multirow{3}{*}{ Anterior } & Group 1 & 22.25 & - & 0.75 & 1.88 & \multirow{3}{*}{3.73} \\
\hline & & Group 2 & 23.00 & & - & 1.13 & \\
\hline & & Group 3 & 24.13 & & & - & \\
\hline & \multirow{3}{*}{ Posterior } & Group 1 & 13.50 & - & 0.63 & $3.63 *$ & \multirow{3}{*}{2.03} \\
\hline & & Group 2 & 14.13 & & - & $3.00 *$ & \\
\hline & & Group 3 & 17.13 & & & - & \\
\hline \multirow{15}{*}{$\begin{array}{l}0 \\
0 \\
0\end{array}$} & \multirow{3}{*}{ Pain } & Group 1 & 38.53 & - & $15.29 *$ & $22.58^{*}$ & \multirow{3}{*}{3.53} \\
\hline & & Group 2 & 53.82 & & - & $7.29 *$ & \\
\hline & & Group 3 & 61.10 & & & - & \\
\hline & \multirow{3}{*}{ Symptom } & Group 1 & 38.43 & - & $17.41 *$ & $29.42 *$ & \multirow{3}{*}{3.13} \\
\hline & & Group 2 & 55.84 & & - & $12.01 *$ & \\
\hline & & Group 3 & 67.85 & & & - & \\
\hline & \multirow{3}{*}{ ADL } & Group 1 & 35.74 & - & $14.98 *$ & $25.66^{*}$ & \multirow{3}{*}{3.32} \\
\hline & & Group 2 & 50.72 & & - & $10.68^{*}$ & \\
\hline & & Group 3 & 61.40 & & & - & \\
\hline & \multirow{3}{*}{ Sport/Rec } & Group 1 & 29.37 & - & $15.63 *$ & $29.39 *$ & \multirow{3}{*}{3.70} \\
\hline & & Group 2 & 45.00 & & - & $13.76^{*}$ & \\
\hline & & Group 3 & 58.76 & & & - & \\
\hline & \multirow{3}{*}{ QOL } & Group 1 & 33.61 & - & $15.62 *$ & $31.23 *$ & \multirow{3}{*}{2.81} \\
\hline & & Group 2 & 49.23 & & - & $15.61^{*}$ & \\
\hline & & Group 3 & 64.84 & & & - & \\
\hline
\end{tabular}

* Level of significance at 0.05

\section{Conclusion}

Maximum improvement in knee measurements was detected with the third experimental groups, compared with the second and the first groups, after six weeks of treating using different treating programs. The combined effect of using static traction in some therapeutic methods to reduce knee arthritis symptoms was the most effective method for reducing the pain and improving the quality of patients' life.

\section{References:}

1. Alberca A. C., -Riquelme J. A. L., Cortés M. P. S.2017. Pain treatment with cooled radiofrequency in osteoarthritis and total knee arthroplasty: case series 
in hospital Universitario de Son Espases. Clinical trials in degenerative diseases, $\mathbf{4 ( 2 )}$.

2. Alpayci M., Ozkan Y., Yazmalar L. 2013. A randomized controlled trial on the efficacy of intermittent and continuous traction for patients with knee osteoarthritis. Clinical rehabilitation, 27: 347-354.

3. Bardoloi B., Bhutia C., Bhatia D., and Paul S. 2017. Knee osteoarthritis: An overview of recent interventions. Journal of biomedical engineering and biosciences, 4.

4. Bhatia D., Bejarano T., and Mario Novo.2013. Current interventions in the management of knee osteoarthritis. Journal of pharmacy and bioallied science., 5(1): 30-38.

5. Bidonde J., Busch A.J., Schachter C.L., Overend T.J., KimS.Y., Góes S.M., Boden C. and Foulds H.J.A.2017. Aerobic exercise training for adults with fibromyalgia (Review). Cochrane database of systematic reviews, $\mathbf{6}$.

6. Brazilian Association of Physical Medicine and Rehabilitation (BAPMR). 2013. Chronic nonspecific low back pain: Rehabilitation. Revista da associacao medica Brasileira, 59(6):536-553.

7. Brosseau L., Yonge K. , Robinson V., Marchand S., Judd M., Wells G. and Tugwell $\mathbf{P}$. 2003. Thermotherapy for treatment of osteoarthritis. Cochrane database system review, 4522(3): 1 .

8. Brosseaul L., Yonge K.Marchand S. Robinson V., Wells G. and Tugwell P. 2004. Effecincy of transcutaneous electrical nerve stimulation for osteoarthritis of the lower extremities: A meta- analysis. Physical therapy reviews, 9: 213-233.

9. Buckwalter J. A. and lane N. E. 1997. Athletics and osteoarthritis. The American journal of sports medicine 25(6):873-81.

10.Buuren F. V., Horstkotte D., Mellwig K. P., Fru“ nd A., Vlachojannis M., Bogunovic N., Dimitriadis Z., Vortherms J., Humphrey R. and Niebauer J.2015. Electrical myostimulation (EMS) improves glucose metabolism and oxygen uptake in type 2 diabetes mellitus patients-results from the EMS study. Diabetes technology and theraputeic, 17(6). 
11.Castrogiovanni P. and Musumeci G.2017. Which is the best physical treatment for osteoarthritis? Journal of functional morphology and kinesiology, 1: 54-68.

12.Costa P. B., Medeiros H. B. O. and Fukuda D. H.2011. Warm-up, stretching, and cool-down strategies for combat sports. Strength and conditioning journal, 33(6).

13.Eitner A., Hofmann G. O. and Schaible H. G.2017. Mechanisms of osteoarthritic pain. Studies in humans and experimental models. Frontiers in molecular neuroscience, $\mathbf{1 0}$ (349).

14.Giggins O.M., Fullen B.M. and Coughlan G.F.2012. Neuromuscular electrical stimulation in the treatment of knee osteoarthritis: a systematic review and meta-analysis. Clinical Rehabilitation, 0(0) 1-15.

15.Hancock G. E., Hepworth T. and Wembridge K. 2018. Accuracy and reliability of knee goniometry methods. Journal of experimental orthopaedics, 5:46.

16.Hasegawa S., Kobayashi M., Arai R. and Tamaki A.2011. Effect of early implementation of electrical muscle stimulation to prevent muscle atrophy and weakness in patients after anterior cruciate ligament reconstruction. Journal of electromyography and kinesiology: official journal of the international society of electrophysiological kinesiology, 21(4):622-30.

17.Intema F., Roermund V.P.M., Marijnissen A.C. 2011. Tissue structure modification in knee osteoarthritis by use of joint distraction: an open 1-year pilot study. Ann Rheum Dis, 70: 1441-1446.

18.Jagtap V. and Shanmugam S.2014. Effect of mechanical traction in osteoarthritis knee. International journal of science and research, 3(10).

19.Karthikeyan T. and Moorthy A. S.2016. Efficiency of therapeutic electrical muscle simulation treating hamstrings muscles strain by functional sports rehabilitation prescribed protocols. Indian journal of physiotherapy, 4(1).

20.Kunduracilar Z. and Selici K.2018. Cardiovascular and functional capacity of patients with knee osteoarthritis. Osteoarthritis biomarkers and treatments. 
21.Kuyucu E., Bülbül M., Kara A., Koçyi F. and Erdil M.2015. Is cold therapy really efficient after knee arthroplasty? Annals of medicine and surgery, 4475 $-478$.

22.Lee D. Y. and Lee N. Y. 2018. Case study of continuous knee joint traction treatment on the pain and quality of life of patients with degenerative gonarthritis. The journal of physical therapy science, 30: 848-849.

23.McGowan C. J., Pyne D. B., Thompson K. G. and Rattray B.2015. Warmup strategies for sport and exercise: Mechanisms and applications. Sports med.

24.Mentiplay B. F., Perraton1 L. G., Bower1 K.J., Adair B., Pua Y. H., Williams G. P., Gaw R. M. , Clark R. A. 2015. Assessment of lower limb muscle strength and power using hand-held and fixed dynamometry: A reliability and validity study. Plos one, 10(10).

25.Pandya M. R. and Sheth M. S. 2.17.Effect of mechanical traction on pain and function in subjects with osteoarthritis knee. International journal of physiotherapy and research, 5(4):2198-02.

26.Pereir D., Ramose E. and Branco J. 2015. Osteoartrite. Acta médica portuguesa, 28(1):99-106.

27.Rongsawad K. and Ratanapinunchai J. 2018. Effects of very high stimulation frequency and wide-pulse duration on stimulated force and fatigue of quadriceps in healthy participants. Annals of rehabilitation medicine, 42(2):250-259.

28.Roos E. M. and Lohmander L. S.2003. The knee injury and osteoarthritis outcome score (KOOS): from joint injury to osteoarthritis. Health and quality of life outcomes, 1:64.

29.Shehata A. E. and Fareed M. E.2013. Effect of cold, warm or contrast therapy on controlling knee osteoarthritis associated problems. International journal of medical and health sciences, 7(9).

30.Shehata A.E. and Fareed M.E. 2013. Effect of cold, warm or contrast therapy on controlling knee osteoarthritis associated problems. World academy of science, engineering and technology international journal of medical and health sciences, 7 (9). 
31.Samuel S. R. and Maiya G. A .2015. Application of low frequency and medium frequency currents in the management of acute and chronic pain-A narrative review. Indian journal of palliat care, 21(1): 116-120.

32.Silva A. E. L., Martimbianco A. L. C., Pontin J. C. B., Filh G. L. L. M C. and Chamlian T. R.2014. Reproducibility analysis of knee circumference in individuals with osteoarthritis. Acta Fisiatr, 21(2):49-52.

33.Sisto S.A. and Malanga G. 2006. Osteoarthritis and therapeutic exercise. American journal of physical medicine and rehabilitation, 85:69-S78.

34.Syed S. and Wani S.2014. Effect of two different manual therapy protocols on osteoartrite knee pain and functional disability: A comparative study .Romanian journal of physical therapy, 20 (34).

35.Teichtahl A., Wluka A., Cicuttini F. M.2003. Abnormal biomechanics: a precursor or result of knee osteoarthritis? British journal of sports medicine.

36. Wheaton M. T. and Jensen N.2010. The ligament injury connection to osteoarthritis. Journal of Pprolotherapy, (2)1:294-304.

37.Yildiz S. K., ÖZkan F. U., AKtas I., Şilte A. D., KAysin M. Y. and Badur N. B.2015. The effectiveness of ultrasound treatment for the management of knee osteoarthritis: a randomized, placebo-controlled, double-blind study. Turkish Journal of medical sciences, 45: 1187-1191. 